\title{
Job Burnout and Its Relevant Factors among Medical Interns
}

\author{
Yongmei Hou* Haojun $\mathrm{Fu}$ \\ Department of Psychology, School of Humanity and Administration, Guangdong Medical University, \\ Dongguan 523808, Guangdong Province, China
}

\begin{abstract}
Objective: to understand the present situation of job burnout among medical interns and to explore its major influencing factors. Methods: A stratified random sampling was used to select 1268 medical interns from 6 full-time medical colleges in Guangdong province. They were investigated with Maslach Burnout Inventor-General Survey, (MBIGS), Questionnaire on Humanistic Care Ability of Medical Students (QHCAMS) and a self-compiled personal information questionnaire. Results: (1) The incidence of job burnout in this group was $98.40 \%$. The total score of MBI-GS and the scores of emotional exhaustion, cynicism and reduced personal accomplishment were $(45.27 \pm 12.61),(16.21 \pm 4.91)$, (12.91 \pm 3.93$)$ and $(18.15 \pm 5.22)$, respectively. (2) The result of multiple stepwise linear regression showed that gender, specialty, type of internship hospital, working department and average length of overtime per day were positively correlated with the total score of MBI-GS $(\beta=.154 \sim .676$, all $\mathrm{P}$ $<0.01)$. Nine factors, such as self-evaluation of health status, ability to solve problems at work, relationship with patients, classmates and medical staff, as well as the scores of hope, honesty, humility and courage in HQCAMS, were negatively correlated with the total score of MBI-GS ( $\beta$ $=-.148 \sim-.468$, all $\mathrm{P}<0.01)$. Conclusion: Medical interns are suffering serious job burnouts, which may be related to work pressure, personal quality and other factors.
\end{abstract}

Keyword: Medical Interns, Job Burnout, Relevant Factors

\section{Introduction}

The internship is an important transitional stage for medical students to change from a student to a clinical practitioner. Successful adaptation during this stage is of great significance for medical students to establish a proper professional attitude, strengthen professional aspiration, improve work enthusiasm and work efficiency, and promote career development. However, medical interns are found to suffer great mental stresses and are prone to job burnouts because of their incomplete and immature professional skills, insufficient psychological preparation and incompetence in work. Researches showed that the incidence of job burnout among medical interns in China is more than 70.9\% [1-4]. With regard to the influencing factors of job burnout, previous studies have mostly focused

\footnotetext{
* Corresponding author: 2184456621@,qq.com
} 
on a limited number of demographic factors, but comprehensive studies on the combination of demographic factors and psychosocial factors are few.

Based on the above analysis, this study intends to adopt a large sample and multi-center investigation model to make a comprehensive analysis of this problem from many aspects, such as demographic factors, psychosocial factors, and so on.

\section{Objects and methods}

\subsection{Objects}

Stratified random sampling was used to select medical interns from 6 full-time colleges (Southern Medical University, Guangzhou University of Traditional Chinese Medicine, Guangdong Medical University, Guangzhou Medical University, Guangdong Pharmaceutical University and Shenzhen University Health Science Center) as the study objects. 1300 questionnaires were sent out and 1268 valid questionnaires were collected, with an effective rate of $97.54 \%$. Among them, 1237 were from Han nationality, 31 from ethnic minorities, 233 from Southern Medical University, 345 from Guangzhou University of Traditional Chinese Medicine, 274 from Guangdong Medical University, 138 from Guangzhou Medical University, 156 from Guangdong Pharmaceutical University, 122 from Shenzhen University Health Science Center; 1094 are only-child, 174 are non-only-child; 2 from rich family, 652 from well-off family, 523 from poverty-line family, and 72 from needy family; 763 from urban areas, 505 from rural areas; 46 academically excellent, 636 academically moderate, 495 academically intermediate, 88 passing score and 3 failed.

\subsection{Tools}

\subsubsection{Maslach Burnout Inventory - General Survey $(M B I-G S)$}

It was compiled by Maslach et al. (1984) and revised by Li Chaoping to the Chinese version [5]. There were 15 items, divided into 3 dimensions: emotional exhaustion, cynicism and reduced personal accomplishment. The Likert 7-point scoring method is used to score from 0 (never)-6 (daily). The higher the score, the more obvious the burnout tendency. The critical values of emotional exhaustion, cynicism and reduced personal accomplishment were 25 points, 11 points and 16 points, respectively. If all the three dimensions < the critical value, the objects would be considered not suffer burnout; if one of the three dimensions $\geq$ critical value, the object would be considered suffer mild burnout; if two of the three dimensions $\geq$ critical value, the object would be considered suffer moderate burnout; and if all of the three dimensions $\geq$ critical value, the objects would be considered suffer serious burnout. The average score of the scale (dimension) below 3 indicates low job burnout, 3-5 indicates serious job burnout, and more than 5 indicates very serious job burnout. In this study, the Cronbach $\alpha$ coefficient of the total scale was 0.89 , and the Cronbach $\alpha$ coefficient of the three dimensions was $0.80-0.84$.

\subsubsection{Questionnaire on Humanistic Care Ability of Medical Students (QHCAMS)}

It was compiled by Shen Zhengfu el. (2013) [6], involving 42 items and 7 dimensions, namely, altruism, honesty, courage, trust, patience, humility and hope. The Likert 5-point scoring method is used to score from 1 (not at all) to 5 (completely yes). The higher the total score, the more obvious the trendency in this dimension (item). In this study, the 
Cronbach'a coefficient of the total questionnaire was 0.85 , and the Cronbach $\alpha$ coefficient of 7 dimensions was $0.77-0.83$.

\subsubsection{Self-compiled Personal Information Questionnaire}

The CNKI, Wanfang database, VIP database, Baidu, Pubmed and other search engines were used to search the literatures about the burnout among medical interns (277 in Chinese and 2421 in foreign languages). Based on that, the basic contents of the questionnaire were constructed, with a total of 19 items. Combined with the results of 3 collective discussions with 10 representatives of medical interns and 5 experts in the field of higher medical education, 4 items were deleted and 3 items were added. It involves 18 items, which include gender, age, nationality, school, specialty, family status (only-child or not), family financial status, origin, academic achievement, type of internship hospital, working department, length of overtime every day, ability to solve problems at work, relationship with patients and medical staff and classmates, self-assessment of personality and health status and so on.

\subsection{Data manipulation}

SPSS 20.0 was used for statistical analysis. Descriptive statistics were used to calculate the average score and standard deviation of each scale; independent sample t-test, Pearson product correlation and one-way ANOVA were used to explore the correlation between variables; multiple stepwise linear regression was used to analyze the related factors of MBI-GS total score.

\section{Results}

\subsection{Descriptive statistics of the total score and factor score of each scale}

The incidence of job burnout in this group was $98.40 \%$. Among them, there were 946 (74.6\%) with mild burnout, 238 (18.5\%) with moderate burnout and 67 (5.3\%) with serious burnout.

As can be seen from Table 1, the overall level of job burnout in this group is on the high side (MBI-GS total score $=3.95 \pm 0.84$ ). 
Table1. Descriptive statistics of the scores of each scale $(n=1268)$.

\begin{tabular}{|c|c|c|c|c|c|c|c|}
\hline Dimensions & Min & $\operatorname{Max}$ & M & SD & $\begin{array}{l}\text { Number } \\
\text { of items }\end{array}$ & $\begin{array}{l}\text { Average } \\
\text { score of } \\
\text { each item }\end{array}$ & $\begin{array}{l}\text { Standard } \\
\text { deviation of } \\
\text { each item }\end{array}$ \\
\hline total score of & 35.00 & 87.00 & 45.27 & 12.61 & 15 & 3.95 & 0.84 \\
\hline $\begin{array}{l}\text { MBI-GS } \\
\text { emotional } \\
\text { exhaustion }\end{array}$ & 5.00 & 31.00 & 16.21 & 4.91 & 5 & 4.04 & 0.98 \\
\hline $\begin{array}{l}\text { reduced } \\
\text { personal } \\
\text { accomplishme } \\
\text { nt }\end{array}$ & 6.00 & 31.00 & 18.15 & 5.22 & 6 & 3.86 & 0.87 \\
\hline cynicism & 5.00 & 24.00 & 12.91 & 3.93 & 4 & 3.98 & 0.99 \\
\hline $\begin{array}{l}\text { total score of } \\
\text { QHCAMS }\end{array}$ & 91.00 & 210.00 & 144.74 & 18.98 & 42 & 3.44 & 0.45 \\
\hline altruism & 7.00 & 25.00 & 16.86 & 3.09 & 5 & 3.37 & 6.17 \\
\hline honesty & 7.00 & 25.00 & 17.26 & 3.61 & 5 & 3.45 & 0.72 \\
\hline courage & 7.00 & 25.00 & 16.34 & 2.97 & 5 & 3.27 & 0.59 \\
\hline trust & 13.00 & 40.00 & 27.61 & 4.56 & 8 & 3.45 & 0.57 \\
\hline patience & 13.00 & 35.00 & 24.72 & 4.58 & 7 & 3.53 & 0.65 \\
\hline humility & 11.00 & 35.00 & 24.46 & 4.60 & 7 & 3.50 & 0.66 \\
\hline hope & 5.00 & 25.00 & 17.49 & 3.86 & 5 & 3.44 & 0.45 \\
\hline
\end{tabular}

\subsection{Correlation Analysis between the scores of each scale}

From Table 2, it can be found that there is a significant pairwise correlation between the total score of MBI-GS (together with the scores of 3 dimensions) and the total score of QHCAMS (together with the scores of 7 dimensions). 
Table 2. Analysis of Correlation between MBI-GS and QHCAMS Scores ( $\mathrm{n}=1268)$.

\begin{tabular}{|c|c|c|c|c|c|c|c|c|c|c|c|c|}
\hline Dimension & 1 & 2 & 3 & 4 & 5 & 6 & 7 & 8 & 9 & 10 & 11 & 15 \\
\hline 1MBI-GS & 1 & & & & & & & & & & & \\
\hline $\begin{array}{l}2 \text { emotional } \\
\text { exhaustion }\end{array}$ & $.884^{* *}$ & 1 & & & & & & & & & & \\
\hline $\begin{array}{l}3 \text { reduced } \\
\text { personal } \\
\text { accomplishment }\end{array}$ & $.930^{* *}$ & $.719^{* *}$ & 1 & & & & & & & & & \\
\hline 4 cynicism & $.870^{* *}$ & $.630^{* *}$ & $.756^{* *}$ & 1 & & & & & & & & \\
\hline 5 altruism & ${ }^{-}$ & $.156^{* *}$ & $\overline{-}^{-}$ & $.165^{* *}$ & 1 & & & & & & & \\
\hline 6 honesty & $\overline{-}^{-}$ & $\overline{-}^{-} 4^{* *}$ & $.297^{* *}$ & $\overline{-}^{-} .1^{* *}$ & $.302^{* *}$ & 1 & & & & & & \\
\hline 7 courage & 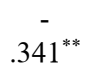 & $-{ }^{-} .11^{* *}$ & $.298^{* *}$ & -.052 & $.164^{* *}$ & $.183^{* *}$ & 1 & & & & & \\
\hline 8 trust & $.242^{* *}$ & $\overline{-}^{-} 196^{* *}$ & $.199^{* *}$ & $\overline{-}^{-}$ & $.299^{* *}$ & $.398^{* *}$ & $.239^{* *}$ & 1 & & & & \\
\hline 9 patience & $.294^{-}$ &.$\overline{1}^{-}$ & $.260^{* *}$ &.$\overline{-}^{-}$ & $.388^{* *}$ & $.482^{* *}$ & $.253^{* *}$ & $.496^{* *}$ & 1 & & & \\
\hline 10 humility & $.334^{* *}$ & $.231^{* *}$ &.${ }^{-}$ & $.3 \overline{7} 0^{* *}$ & $.300^{* *}$ & $.471^{* *}$ & $.252^{* *}$ & $.526^{* *}$ & $.562^{* *}$ & 1 & & \\
\hline 11 hope & $\stackrel{-}{.377^{* *}}$ & ${ }^{-}-$ &.- &. & $.304^{* *}$ & $.461^{* *}$ & $.150^{* *}$ & $.492^{* *}$ & $.503^{* *}$ & $.558^{* *}$ & 1 & \\
\hline 12 HQCAMS & 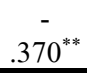 & $.276^{* *}$ & $.325^{* *}$ & $.410^{* *}$ & $.553^{* *}$ & $.692^{* *}$ & $.437^{* *}$ & $.746^{* *}$ & $.793^{* *}$ & $.794^{* *}$ & $.724^{* *}$ & 1 \\
\hline
\end{tabular}

Note: ${ }^{*} \mathrm{P}<0.05, \quad * * \mathrm{P}<0.0$ 


\subsection{Multiple stepwise linear regression analysis of factors related to job burnout among medical interns}

\subsubsection{Variable Assignment}

First, values are assigned to the possible situations (alternative answers) of demographic and psychosocial classification variables that may affect the total score of MBI-GS, and the results are shown in Table 3.

Table 3. Variable Assignment.

\begin{tabular}{|c|c|}
\hline item & Options and variable assignment \\
\hline 1.nation & $0=$ minority minorities; $1=$ Han nationality \\
\hline 2.gender & $0=$ male $; 1=$ female \\
\hline 3.school & $\begin{array}{l}0=\text { Southern Medical University; } 1=\text { Guangzhou University of Traditional Chinese } \\
\text { Medicine; } 2=\text { Guangdong Medical University; } 3=\text { Guangzhou Medical University; } \\
\text { 4=Guangdong Pharmaceutical University; } 5=\text { Shenzhen University Health Science } \\
\text { Center }\end{array}$ \\
\hline 4.specialty & $\begin{array}{l}0=\text { Oral Medicine; } 1=\text { Preventive Medicine; } 2=\text { Medical Examination; } 3=\text { Pharmacy; } \\
4=\text { Nursing } 5=\text { Anesthesiology } 6=\text { Clinical Medicine }\end{array}$ \\
\hline $\begin{array}{l}\text { 5. From only-child } \\
\text { family or not }\end{array}$ & $0=$ no; $1=$ yes \\
\hline $\begin{array}{l}\text { 6. Family financial } \\
\text { status }\end{array}$ & $0=$ rich $; 1=$ moderate $; 2=$ poverty-line $; 3=$ poor \\
\hline 7. origin & $0=$ urban area; $1=$ rural areas \\
\hline $\begin{array}{l}\text { 8. academic } \\
\text { performance }\end{array}$ & $0=$ failed $; 1=$ passed $; 2=$ medium; $3=$ moderate $4=$ excellent \\
\hline $\begin{array}{l}\text { 9. Type of internship } \\
\text { hospital }\end{array}$ & $0=$ fiest class; $1=$ second class; $2=$ tertiary \\
\hline 10.working & $0=$ Department of Internal Medicine; $1=$ Department of Obstetrics \& Gynecology; $2=$ \\
\hline department & $\begin{array}{l}\text { Department of Pediatrics; } 3=\text { Surgical Department; } 4=\text { Department of psychiatry; } 5= \\
\text { Department of Infectious Diseases; } 6=\mathrm{ICU}\end{array}$ \\
\hline $\begin{array}{l}\text { 11. Average length of } \\
\text { overtime per day }\end{array}$ & $0=0$ hour; $1=$ within 1 hour; $2=1-2$ hours; $3=2-3$ hours; $4=$ More than 3 hours \\
\hline $\begin{array}{l}\text { 12. Ability to solve } \\
\text { problems at work }\end{array}$ & $0=$ Almost can't; $1=$ Mostly can't; $2=$ Mostly can; $3=$ Totally can \\
\hline $\begin{array}{l}\text { 13. Relationship with } \\
\text { patients }\end{array}$ & $0=$ Not sure; $1=\mathrm{Bad} ; 2=$ Moderate $3=$ Good $; 4=$ Great \\
\hline $\begin{array}{l}\text { 14. Relationship with } \\
\text { medical staff }\end{array}$ & $0=$ Not sure; $1=\mathrm{Bad} ; 2=$ Moderate; $3=$ Good $; 4=$ Great \\
\hline $\begin{array}{l}\text { 15. Relationship with } \\
\text { classmates }\end{array}$ & $0=$ Not sure $; 1=\mathrm{Bad} ; 2=$ Moderate $3=$ Good $; 4=$ Great \\
\hline $\begin{array}{l}\text { 16. self-assessment of } \\
\text { personality }\end{array}$ & $0=$ extraversion, $1=$ introversion \\
\hline
\end{tabular}


17. Self-assessment of $0=$ not well; $1=$ moderate $; 2=$ strong

health status

\subsubsection{Multiple stepwise linear regression analysis of factors related to job burnout among} medical interns

Taking the total score of MBI-GS as the dependent variable, the 7 dimensions of QHCAMS and 18 factors that may be related to the total score of MBI-GS (including demographic variables and psychosocial factors) as independent variables, a multiple stepwise linear regression was carried out within $95 \%$ confidence interval.

From Table 3, it can be found that gender, specialty, type of internship hospital, working department and average length of overtime per day were positively correlated with the total score of MBI-GS $(\beta=.154 \sim .676$, all $P<0.01)$. Nine factors, such as selfevaluation of health status, ability to solve problems at work, relationship with patients, classmates and medical staff, as well as the scores of hope, honesty, humility and courage, were negatively correlated with the total score of MBI-GS $(\beta=-.148 \sim-.468$, all $P<0.01)$.

Table 4. Multiple stepwise linear regression analysis of factors related to job burnout among medical interns.

\begin{tabular}{|c|c|c|c|c|c|c|c|c|}
\hline $\begin{array}{l}\text { Dependent } \\
\text { Variable }\end{array}$ & $\begin{array}{l}\text { Independent } \\
\text { variables }\end{array}$ & B & $\mathrm{SE}$ & $\beta$ & $t$ value & $P$ value & $R^{2}$ & $R_{a d j}^{2}$ \\
\hline MBI-GS & Gender & .267 & .045 & .154 & 7.623 & $<.001$ & .508 & .503 \\
\hline \multirow{13}{*}{$\begin{array}{l}\text { Total } \\
\text { score }\end{array}$} & specialty & .381 & .069 & .312 & 2.999 & .005 & & \\
\hline & $\begin{array}{l}\text { Type of } \\
\text { internship }\end{array}$ & .427 & .116 & .374 & 2.766 & .008 & & \\
\hline & $\begin{array}{l}\text { hospital } \\
\text { working } \\
\text { department }\end{array}$ & .683 & .144 & .599 & 3.863 & $<.001$ & & \\
\hline & $\begin{array}{l}\text { average } \\
\text { length of } \\
\text { overtime per } \\
\text { day }\end{array}$ & .485 & .132 & .402 & 4.899 & $<.001$ & & \\
\hline & $\begin{array}{l}\text { self- } \\
\text { evaluation of } \\
\text { health status }\end{array}$ & -.313 & .051 & -.302 & -5.209 & $<.001$ & & \\
\hline & $\begin{array}{l}\text { ability to } \\
\text { solve } \\
\text { problems at } \\
\text { work }\end{array}$ & -.753 & .105 & -.676 & -2.785 & .005 & & \\
\hline & $\begin{array}{l}\text { relationship } \\
\text { with patients }\end{array}$ & -.440 & .196 & -.386 & -4.464 & $<.001$ & & \\
\hline & $\begin{array}{l}\text { relationship } \\
\text { with medical } \\
\text { staff }\end{array}$ & -.528 & .213 & -.468 & -5.095 & $<.001$ & & \\
\hline & $\begin{array}{l}\text { relationship } \\
\text { with } \\
\text { classmates }\end{array}$ & -.344 & .092 & -.284 & -3.900 & $<.001$ & & \\
\hline & hope & -.257 & .055 & -.236 & -4.706 & $<.001$ & & \\
\hline & honesty & -.173 & .055 & -.148 & -3.132 & .002 & & \\
\hline & humility & -.202 & .066 & -.158 & -3.084 & .002 & & \\
\hline & courage & -.224 & .043 & -.191 & -5.116 & $<.001$ & & \\
\hline
\end{tabular}




\section{Discussion}

This study found that medical interns suffered a rather high level of job burnout, with the average MBI-GS score being $3.95 \pm 0.84,98.40 \%$ of the medical interns suffered from job burnout, which was consistent with the results of previous studies [1-4]. The result suggests that job burnout is a common psychological problem among the medical interns in China.

The results of multiple stepwise linear regression showed that gender, specialty, type of internship hospital, working department and average length of overtime per day were positively correlated with the total score of MBI-GS. Nine factors, such as self-evaluation of health status, ability to solve problems at work, relationship with patients, classmates and medical staffss, as well as hope, honesty, humility and courage, were negatively correlated with the total score of MBI-GS.

Girls suffer higher level of job burnout than boys, which is consistent with the findings of Shu Xianzhu [4]. It is suggested that there are gender differences in occupational adaptation. Job burnout is a negative mood and behavioral reaction caused by the inability to tackle the stress at work. Besides, girls are less capable in anti-frustration and emotion regulation than boys [7]. Stress will bring about greater and more lasting stress on girls, resulting in excessive activation of negative emotions [8]. Therefore, it is concluded that girls are more likely to suffer job burnout.

It is also found that specialty, the type of hospital, the working department, the average length of overtime per day are positively correlated with the total score of MBI-GS, which is consistent with the research results of Shu Xianzhu [4]. The above 5 factors reflect the objective work stress from different angles, such as work task, work content, work standard, workload and so on, which have positive predictive effects on the job burnout of the enrolled medical staff. The result has been confirmed by a large number of literatures [914]. Once again, this study confirmed that the results also have a positive predictive effect on the job burnout of medical interns, suggesting that objective job stresses have a generally positive predictive effect on job burnout among medical workers.

Lastly, it was found that such nine factors as self-evaluation of health status, ability to solve problems at work, relationship with patients, classmates and medical staff, and QHCAMS's hope, honesty, humility and courage, were negatively correlated with the total score of MBI-GS. The result is consistent with the findings of previous studies [4,15], suggesting that good personal qualities (physical health status, ability to solve problems at work, personality traits, interpersonal relationships, etc.) are helpful to reduce the job burnout among medical interns.

\section{References}

1. $\mathrm{H} \mathrm{Li}, \mathrm{B} \mathrm{R} \mathrm{Liu}, \mathrm{X} \mathrm{M} \mathrm{Liu}$, et al. Initial investigation about occupational lassitude condition of clinical interns and nursing students, China Higher Medical Education, 7, 62-64 (2011)

2. H Song, W Xu. A Study on the relationship between achievement motivation and job burnout of medical interns, China Higher Medical Education, 5, 62-64 (2015)

3. L J Yang, Q L Peng, X N Zhou. Analysis of job burnout situation in TCM medical interns from perspective of emotion regulation self-efficacy, Journal of Changchun University of Chinese Medicine, 31(6), 1288-1290 (2015)

4. X Z Shu, T D Huang, N C Fan, et al. Correlation of occupational burnout with social support and copying style among interns of a medical college in Sichuan, Pract Prev Med, 23(11), 1340-1344 (2016) 
5. $\mathrm{C} \mathrm{P} \mathrm{Li}, \mathrm{K}$ Shi. The influence of distributive justice and procedural justice on job burnout, Acta Psychologica Sinica, 35(5), 677-684 (2003)

6. Z F Shen, X M Yang, H X Han, et al. Preparation and application of questionnaire on humanistic care ability of medical students, Journal of the Third University, 15, 77-80 (2013)

7. M R Wang, L Zeng. An empirical study on the psychological characteristics of post90s female college students -- Based on the comparison with male college students, China Youth Study, 4, 67-72 (2014)

8. $\mathrm{Y} \mathrm{H} \mathrm{Hu}, \mathrm{M}$ Huang, Diverse consequences of neuroticism and extraversion on down_regulation of negative emotions, ctaPsychologicaSinica, 38(4), 553-561 (2006)

9. R Gashmard, R Bagherzadeh, S Pouladi, et al. Burnout and its related demographic factors among the medical staff working in hospitals associated with Bushehr University of medical sciences, Puerto Rico Health Sciences Journal, 34(4) (2015)

10. X Y Zhou, J C Pu, X Zhong, et al. Burnout, psychological morbidity, job stress, and job satisfaction in Chinese neurologists, Neurology, 88(18), 1727- 1735 (2017)

11. L Y Zhang, J M Zhang, Y F Gao, et al. Comparative Study on the Status of Doctors ' and Nurses ' Job Burnout and Its Influence Factors, China Journal of Health Psychology, 19(11), 1345-1347 (2011)

12. Hao Cheng, H Ma, N Zhang. The status of occupational burnout among doctors in west China and its relationship with work-family conflict, Chinese Journal of Behavioral Medical Science, 21(3), 262-264 (2012)

13. J M Zhang, J Q Sun, Q L Liu, et al. Investigation on Job Burnout of nurses in general hospitals, Journal of Ningxia Medical University, 37(2), 216-218 (2015)

14. C B Wu. Research on Occupational Burnout and Resilience of Psychiatric and Nonpsychiatric Medical Staff, Ma.D. Thesis, Jining Medical University (2019)

15. X Feng, H T Li. Research on quality education of medical students based on the prevention of job burnout, NORTHWEST MED.EDU, 22(5), 929-930 (2014) 